\title{
STRATEGIC MANAGEMENT IN TIMES OF CRISIS
}

\author{
Maximilian Groh \\ Institute of Economics of the Polish Academy of Sciences, Warsaw, Poland
}

Received 2014-05-31; Revised 2014-06-14; Accepted 2014-06-27

\begin{abstract}
This aim of this article is to identify unusual strategic-management matters in times of crisis. The research scope is strategic management processes, the characteristics of the processes and methods of strategic crisis management. The study reports research on the contemporary state of strategic crisis-management problems and provides an analysis of some theoretical and methodological principles. The analysis includes a classification of the main problems which must be solved for efficient, strategic, crisis management. The article indicates strategic and tactical management methods used by corporations and raises questions about the functional distribution of strategic management within relevant authorities; it makes practical recommendations for the functional realization of strategic management goals at all stages of a crisis; it identifies the responsible supervisory entities and the main results of strategic management. The range of problems of the subsystems of strategic management in a crisis period is researched; a basic set of strategic competences of the management authorities is found; and the functional distribution of strategic management in crisis conditions is shown. The suggested mechanism for strategic management in crisis situations is the instrument for the prevention and liquidation of crisis phenomena; it increases the efficiency of the adoption and realization of strategic plans to counter crises. Using planned scenarios and mechanisms to run corporations during a crisis may provide the opportunity to maintain strict governance of the actions of corporate top management and to identify the main tasks for neutralizing crisis events as they develop during the crisis situation. Quick and effective implementation of the set tasks during a crisis will help a corporation to increase the efficiency of its anti-crisis measures.
\end{abstract}

\section{Keywords: Corporation, Crisis, Strategic-Management Methods, Strategic Leadership, Strategic Management}

\section{INTRODUCTION}

Crises in the world economy attract the attention of theoreticians and practitioners on a range of strategicmanagement problems. The work of a professional and independent committee of directors of major world business corporations is based on the principles of competence, democracy and clarity. It is often unable to prevent crisis and thus it fails to protect corporations from the most negative developments. In spite of the objective complexity of the management of large hierarchical structures and their predictions, one critical problem is an increase in uncertainty about responsibility for the distribution of power within a major body of strategic managers. First among such problems is the functional distribution of strategic management in a crisis (Weiner, 2006).

Crisis situations are an inseparable attribute of corporate functioning in a market economy (in conditions of economic, financial and political instability). In consideration of it, corporations must adapt to conditions that are due to external environmental factors; internally, managers must determine a plan for anti-crisis corporate activity and adaptation to the situation.

Modern literature about corporate management during crisis events does not properly cover studying and classifying the actions carried out by a corporation's senior managers at different stages and levels of a crisis, or finding out what constitutes timeliness and the value of the research conducted. 


\section{LITERATURE REVIEW}

This Analyzing theoretical sources on crisis issues includes different approaches to the definition of the essence of a crisis and possible reasons of its occurrence.

According to Kindleberger and Aliber (2011), the essence of economic crises is found in overproduction in relation to effective total demand, in a mismatch of social capital, mass company bankruptcies, the rise in unemployment and other social and economic shocks.

As Reinhart and Rogoff (2011), economic crises became regular when commodity production had become a dominating production form, with the market as its spontaneous regulator and when the gap between production and consumption had thus increased. At the same time, (Ferguson, 2012) states, that crises are cyclic (cyclicality is defined as a multifarious event, some of its forms have global character; cyclicality is some kind of provision for the development of an economy in terms of market relationships; cyclicality is considered as a form of progressive development of society; cycles and crises present as a result of developments specific to each country).

Crisis events in business operations happen with an escalation of misunderstandings, which occur as a result of the interaction of microeconomic systems with each other and with the external environment. According to (Cipriani and Guarino, 2008), such misunderstandings are found between:

- $\quad$ The quantity and quality of production (goods and services) and the state of market demand

- Actual and required enterprise productive capacity

- Required volume of resources, which the enterprise needs and the availability of its output (supply), its offer prices and demand for the products

- Actual and planned enterprise revenue distribution aimed at industrial and social development

As Fried (2012), the first indicator of crisis is a distinct trend for increasing current expenses with the opposite trend of a decreasing amount of business, as well as sinking revenues and profits. Here, we mean actual revenue, not tax or accountant's debts, which can be "profitable" for the enterprise (for instance, in terms of tax savings). Misbalance of the required relationship between an enterprise's revenue (profit) and the cost of resources, between money received and money spent, between net worth and loan capital build to a consequence of a crisis state. Further crisis aggravation is characterized by deterioration of all indicators of a corporation's status (quantity as well as quality ones), which leads to gradual loss of net worth (net assets) and the appearance of financial deficiency for the settlement of its obligations.

As Shiller (2012), the start of a crisis demonstrates the development of a gradual imbalance and a complete loss in the capability of internal self-regulation mechanism of the economic system. By the time a crisis appears, the economic system has reached the top of its possible development, where further development within the present paradigm is impossible. The system has exhausted its productive industrial potential and is in conflict with current business mechanisms and property relationships. Depletion of the necessary principles for running a business happens: Material and technical, market and social. It is possible to solve the accumulated disagreements only with thorough revision of all of the fundamental principles for running a business, coordination of the strategic vision of corporate mission and the nature of enterprise activity, which provides a system's transition to a new balanced state, which is a necessary precondition for its further development.

The literature review on this issue also shows that the overwhelming majority of authors deal with the problems of corporate or anti-crisis management. Some authors pay little attention to the adjustments needed when the strategic-management authorities realize that there is an adjustment required (James and Wooten, 2007); others do not take into consideration the behavior of an organization when they begin anti-crisis management, as they concentrate on the problems which must be solved to overcome the crisis, but not on who must find the solutions and in what way (Brace, 2012). The interdisciplinary nature of management (between corporate and anti-crisis management) comes from the research of (Weiner, 2006; Campbell and Sinclair, 2009).

Anti-crisis management policies have been noted and analyzed by (Bacon, 2006; Greyser, 2009; James and Wooten, 2010; Hellsloot, 2007; Pauly and Hutchison, 2005). These authors treat the problems of a crisis and the crisis situation in different ways. For example some scientists study anti-crisis management from the point of view of financial problems at the enterprise level (Hellsloot, 2007) that appear as a negative chain reaction from other enterprises. Others study the problems connected to the crisis of some individual enterprises and they review unfavorable financial conditions in the relevant country's economy (Pauly and Hutchison, 2005).

According to Campbell and Sinclair (2009), strategic management in a crisis is a type of management aimed at 
defining the phenomena of a crisis and creating appropriate preconditions for well-timed prevention, weakening and overcoming of the problems. That activity aims to support the life of the corporation, business activity and the avoidance of bankruptcy. Crisis strategic management is a special system which is complex in character and which can completely neutralize temporal difficulties for a corporation's work (Bacon, 2006).

\section{A CRITICAL PERSPECTIVE}

Crisis strategic management aims to identify the signs of a crisis and to create the necessary prerequisites for their timely prevention, weakening and overcoming in order to guarantee the continuance of the corporation's activity and the prevention of bankruptcy. Strategic management in a time of crisis is the method which makes it possible to recognize the crisis and to take measures to overcome its negative consequences. The techniques of crisis management include a number of consequent steps from the understanding of the influence of the crisis on the corporation to preventing, alleviating and overcoming the different types of crisis. Anti-crisis managers must have clear system vision and they must be able to analyze a number of the interconnected problems that could lead the corporation to bankruptcy or to a worsening of the position of its staff.

The problems that strategic management solves can be presented in the following way. The first group includes the problems of prediction prior to the emergence of a crisis situation. The second group of problems is connected to key aspects of the activity of the organization. The range of problems can be presented by differentiating the management techniques, which is the third problem set. This includes problems of crisis prediction and the variants of behavior of the socioeconomic system in the crisis, the problems of finding necessary information and the development of crisismanagement solutions. The problems of analysis and assessment of crisis situations are important too. The third group includes time limitations, staff qualifications, the methodology and organization of solutions, the shortage of information and the problems of developing innovative strategies that may help to overcome the crisis (Weiner, 2006). The fourth group includes conflict-resolution and the selection of staff in crisis situations.

Crisis strategic management is a special type of management, which has common management features and non-specific characteristics. First, it is necessary to mark out the basic principles of the system of crisis strategic management. Such principles are: The early diagnosis of the crisis in the financial activity of the firm, the speed of the reaction to the crisis phenomena, the adequacy of the reactions to the real threats to financial wealth and the achievment of total potential in order to overcome the crisis.

The main directions of anti-crisis management at the corporate level are the permanent monitoring of socialeconomic conditions, the development of new management techniques, financial and marketing strategies, the reduction of constant and variable costs, the attraction of stockholders' capital and the intensification of staff motivation. There are no standardized methods of preparation for possible global crisis phenomena; however, there is useful experience learned from a previous crisis (Campbell and Sinclair, 2009).

Let us analyze some peculiarities in corporate management during a crisis as exemplified by the Chrysler corporation, founded in 1924 by the famous engineer and businessman Wolter Chrysler.

Chrysler had been actively developing since the late 1950s. In the sixties the corporation acquired European motor companies: In 1963 it bought 40 per cent of the shares of the Spanish company Barreiros Diesel; in 1964 it bought 30 per cent of the shares of the British motor consortium Rootes Group; in 1966-67 it bought approximately 80 per cent of the of shares of the French company Semerka. These companies were named accordingly: 'Chrysler Spain, Chrysler Great Britain, 'Chrysler France'. In combination they became a united motor center-Chrysler in Europe.

In 1970, Mitsubishi Motors produced under Chrysler's brand small economical cars for sale in the United States. But in the 1970s it became unprofitable. This can be explained by both the energy crisis and premature industrial policy, as well as athe launch of a series of unsuccessful models (Dodge Aspen, Plymouth Volare, Dodge St. Regis) and problems with quality as well. In 1977, Chrysler Europe crashed. The company suspended production of these cars.

Note that the seventies crisis was the biggest in the corporation's history. By that time, the question of reforming the enterprise had been discussed for a long time and the following features demonstrated the urgency:

- There were issues with achieving plans

- Consumer research showed that two-thirds of buyers were not satisfied with the quality of the company's cars these cars were chosen mostly by the elderly and from the point of view of young people, Chrysler cars were considered boring. Clients found unattractive both the quality and the design of these cars 
- Senior managers were ignorant about the actual business situation

- There were issues with selection of the staff

From the point of view of the HR and corporate culture, the crisis of the 1970s for Chrysler can be characterized by the following:

- Staff equipment status. Senior management were incompetent and did not have professional skills

- From a cultural point of view, company management was not focused on change

This led to a situation, where an assessment of its own resources and the company status in general was overestimated, but senior managers looked for a reason for their difficult situation in the external environment. Chrysler managed to escape from the crisis and learned a good lesson from this situation. It revealed new opportunities and new sales markers and new consumers. The seventies crisis led to the following changes:

- Senior company management was almost fully renewed and a team of young experienced leaders was gathered

- A communication system was established, which had a positive effect on the system of information distribution within the company

- A system of non-material motivation was created. Due to this system each employer could feel involved in the production process (Lutz, 1999)

Thus, at a crucial time, the Chrysler corporation managed to revitalize its resources and redirect its efforts to reach its desired goal. In 1978 Chrysler Australia was bought by Mitsubishi Motors. The second oil crisis ended. It reduced the numbers of lorry and other truck sales of Chrysler. Without a proper production line of mini-cars, Chrysler nearly faced bankruptcy.

In 1979, the Chrysler Corporation asked a loan from the US government. Trying to solve the situation, the company invited Li Yakokku, a famous manager, who was able to get guarantee of loans from the US government, having proven that closing the works of such a giant corporation as Chrysler would be an American national tragedy. Yakokka reformed management and raised the company profile until 1983. Lamborghini (1987), AMC (American Motors Corporation), with its famous brand Jeep, were acquired by Chrysler. In the period from 1985 to 1989, Chrysler engineered small economy cars together with Mitsubishi
Motors and Renault. Since 1988, a series of passenger cars, trucks and pick-ups under the brand name Eagle have been produced.

In 1998, Chrysler joined with Daimler-Benz, which becomes Daimler-Chrysler. When the Daimler-Benz and Chrysler corporations announced in May, 1998 about asset pooling of 36 billion dollars, many experts found their decision arrogant and almost impossible. They stated that this step could lead to a change in the whole global motor industry. Chrysler was to import in Germany, where Daimler-Benz carried out experiments with its SmartCar, production economy cars. DaimlerBenz engineers in their turn had to revitalize the trademark Chrysler, improve the general quality of its cars, which are produced under common brand and enrich their knowledge about such vehicles as minivans. Combining their efforts, the companies got the opportunity to reduce excessive productive capacity as well as ensuring a leading position on the global motor market, which could help it to compete with General Motors, Ford and Toyota. However, years passed before a new motor giant managed to reach these goals. Such a long time can be mainly explained by the fact that the communication process was complicated due to cultural barriers.

In 2007, Daimler-Chrysler sold its sub-department Chrysler for 7.4 billion dollars to the fund Cerberus.

On April 30 2009, Chrysler announced its technical bankruptcy. After debt payments a part of their shares were sold to Fiat.

Since the beginning of 2014, Chrysler has remained under the full control of an Italian motor concern, Fiat. The General Director is Sergio Markionne (at the same time he holds the position of the head of Fiat). In January 2014, after the complete share consolidation of American Chrysler, the Board of Directors of Fiat confirmed its decision about the development of a new motor company-Fiat Chrysler Automobiles-with headquarters in the Netherlands.

Thus, Chrysler managed to overcome crises by means of working actively with the internal company environment (raw materials, product organization, finance) and with the external environment (getting guarantees of loans). However, deterioration in the external environment in the twentieth century, growing incompetence and changes in consumer demand led Chrysler's management during the crisis to ineffective running of the business (which resulted in bankruptcy).

We turn now to study peculiar features of corporate management practices in a crisis period and work to understand management methods. 


\section{CRITICAL ANALYSIS}

The practice of strategic management can be found from 11 major methods of crisis management. The methods can be divided into two groups in terms of the results which a corporation might expect from their use (see Table 1).

The first group comprises tactical methods. They include readjustment, downsizing and bankruptcy. These methods aim at a quick improvement of corporate financial performance; that is, overcoming crisis consequences. However, the use of these methods is not always enough to remove the causes of the crisis if these are ineffective management systems (Greyser, 2009).

The other group can be (conditionally) called strategic methods. As a rule, a corporation does not immediately see results from these methods, but their use changes the essence of business and qualitative characteristics such as competitiveness, investment attractiveness, customer-orientation and innovation. Methods such as bankruptcy, liquidation, the creation of new corporate structures and modernization are understandable; the other methods need to be explained.

Readjustment is the first method adopted by the majority of corporations that are in crisis. This method combines financial-economic, industrial-technological, organizational and social measures that are aimed at an immediate improvement in the financial growth of firms through changes to the structure of corporate assets and liabilities (James and Wooten, 2007). The readjustment methods are laying-up, leasehold and realization of fixed-asset turnover which the corporations do not use, substitution of short-term debt to long-term debt, devolution of social objects to municipal property and so on.

As a rule, the results of readjustment are temporal in character unless they are fixed by structural reforms. However, it is necessary to remember that readjustment plays the important role of financial improvement for growth in the effectiveness of restructuring and the other methods.

Table 1. Methods of the strategic management in time of crisis

\begin{tabular}{ll}
\hline Tactical methods & Strategic methods \\
\hline 1. Readjustment & 1. Liquidation \\
2. Downsizing & 2. Creation of new \\
& corporate structures \\
3. Bankruptcy & 3. Regularizing \\
& 4. Modernization \\
& 5. Amalgamation \\
& 6. Diversification \\
& 7. Restructuring \\
& 8. Re-engineering \\
\hline
\end{tabular}

Downsizing is another method which can immediately improve rates of corporate activity. This is the decrease in excess capacity and the decrease in the employment of a number of industrial and administrative corporate personnel in line with real demand market. This method leads to considerable cost cutting and a decrease in production prices (Weiner, 2006).

The use of the following methods in the process of crisis strategic management is aimed at improving the qualitative characteristics of corporate activity. The main methods include amalgamation within the bounds of one corporation of different stages of production and distribution and diversification in the types of activity. The methods are only rational if the integration leads to essential savings or to essential decreases in transport costs.

Regularizing is the introduction of contemporary approaches to crisis strategic management. Such approaches include the formation of strategic planning and management accounts, the creation of a combined system of financial controls and planning, computerbased systems of accounting and strong marketing. With the help of these approaches, corporations form management systems which can solve a lot of the problems connected with market conditions and the search for new international markets.

Reengineering appeared at the beginning of 1990 and is now widespread. The main idea is the reconstruction of corporate business processes. Owing to a reduction in unnecessary links and unnecessary expenditures of time and money, reengineering achieves a sharp bounce, the spasmodic increase in effective activity, such as work efficiency, processing time, costs of manufacture and so on.

Restructuring is a complicated method of crisis strategic management that has become widespread recently. This method is connected to changes in organizational structure and the system of strategic management. It is linked to the use of capital for the purpose of economic and organized separation and a sanitation of business processes (types and directions of activity) (PB, 2009). During the restructuring, all business processes use principles such as self-finance and self-administration; they receive a pre-determined degree of economic independence. The corporations use this method only when their current management system cannot achieve effective development in all directions of their corporate activity simultaneously.

Having a number of methods is helpful for two reasons: (i) The presence of several approaches to the anti-crisis strategic management and (ii) the different 
nature of and reasons for the prevailing crisis phenomena. In contrast to the strategic methods, the use of the tactical ones depends on the depth of the crisis and the approaches to anti-crisis management.

Effective strategic management in a time of crisis provides for the combination of the following elements:

- The professional knowledge of members of the organization undertaking strategic management and their awareness of the characteristics of the business's strategic management

- The experience of anti-crisis activity and the work of the anti-crisis groups

- Managerial professionalism

- The anti-crisis activity of the management representatives (Bacon, 2006)

The basic element of strategic management of crisis is the development of a list of interested parties that have responsibility for the success of the functions of anti-crisis management (stockholders' meetings, Board of Directors, executing agency, audit committee). The first condition is the observance of legislative norms and the rules of corporate relationships. The observance of these norms and rules creates the fundamental basis for the maximum provision of the stockholders of the corporation and it also imposes on them certain constraints with regard to their will and their actions. The second element is the necessity for harmonization of the system of strategic management with international management standards. The third element is that it is necessary to take into account the different characteristics of the role of the strategic managers in every corporation relative to devising the functions of anti-crisis management. The role can be:

- Informational-the timely informing of a wide circle of stakeholders about the first signs of crisis phenomena and of the probability of bankruptcy

- Consultative (relative to stockholders and (or) the common stockholders' meetings)-the introductory study of problematic activity of a corporation; the assessment of the degree of influence of the crisis factors from the environment on corporate activity; the formation of strategic anti-crisis alternatives; the complex set of alternative efficient and tactical anti-crisis measures
- Participative-participation in the process of decisionmaking by the other managers of the strategy and the development of alternatives

- Control-the realization of the strategic and efficient control of the anti-crisis programs and plans that are approved by the managers of the strategy and the grouping and participation of managers in the functioning of the control subsystem in the corporation (Bacon, 2006)

Boards of directors must take up their important role in the structuring of the anti-crisis functions in corporations. Unfortunately, the board of directors very often only execute their duty officially. This damages the interests of the stakeholders and has a negative influence on the results of the activity of the corporation, especially in their strategic perspective (Greyser, 2009). The traditional schemes of decisionmaking must not influence the quality of the execution the duty of the board of directors and, further, on the number of board members and the competence of these members. The level and completeness of the structuring of functions depend on the number of stockholders and the number of directors; the development of functions is possible when special committees are created or if external administrative advisers are involved.

\section{PRELIMINARY GUIDLINES}

Strategic crisis management provides that shareholders and managers of corporations must decide on an organizational structure for a subsystem of anti-crisis management and which of its contents to delegate to each member of the strategic management team. The system can make different organizational decisions subject to ensuring an adequate volume of activity, subjective assessments and the preferences of influential stakeholders. It is obligatory to take into account the stage of the crisis in the activity of the corporation. The distribution of the objectives of strategic management at different stages of crisis development is set out in Table 2. It shows the unit of the management team which is responsible for controlling each stage.

The material presented in Table 2 comprises the specification of the methods for achieving anti-crisis management by the governing bodies at different stages of the development of the crisis. It shows practical solutions for problems for strategic crisis management. It provides the governing body with the basic scheme for determining responsibility for identifying separate problems for anti-crisis management. 
Maximilian Groh / American Journal of Economics and Business Administration 6 (2): 49-57, 2014

Table 2. Realization of functions of the strategic management at different stages of development of crisis phenomena

\section{Crisis caution}

№ Problems Content ControlAuthority

$\frac{1}{1}$

A diagnosis of external circumstances

2

Assessment of possible consequences of the influence of negative factors

Realization of preventative measures

\section{Management in conditions of crisis}

$$
\begin{aligned}
& \text { Revelation of } \\
& \text { the signs of crisis }
\end{aligned}
$$

2

The analysis of crisis causes

Monitoring 'weak signals'

from the external

environment, which can

potentially cause crisis

Fulfills control; uses the

results and monitors changes

of factor conditions-

Board of Directors

Assessment of the degree of Evaluates risks of the

influence of crisis factors from governing board; forms

the external environment and measures as counteraction

the determination of the

likelihood of opposition

to such factors

The selection of the program Board of directors

to counteract negative

influences from external

crisis factors

Timely identification

of the first signs of

crisis in corporate activity

Determination and the analysis of crisis causes

The identification the type and the depth of crisis

The realization of anticrisis programs

The analyze of the consequences of anticrisis programs
Diagnostics of subsystem and organization on presence of crisis and depth of crisis phenomena Choice and realization of activity programs in conditions of crisis

The determination and the analyze of actual consequences of plantation of anti-crisis programs
CEO

CEO analyzes and submits for consideration to Board of directors for making decisions

CEO

The program is approved by board of directors which realizes and reports back to the governing CEO submits the results of analyze for consideration to Board

\section{At the stage of overcoming of consequences}

1

$$
\text { The assessment of }
$$

post-crisis situation

The determination of consequences of influence of crisis on a corporate activity
Development of new strategies

Choice and realization of strategy

Determination of controlled Based on information about and uncontrolled crisis factors

\section{corporate activity in}

condition of crisis.

Determination of factors

which are necessary in the sequel to follow, neutralize and adapt

Development of alternative strategies for further basic new progress

Choice among alternative strategies of directors decisions.

Governing submits the results for consideration to Board of directors and the common stockholders' meeting

CEO together with the committee of strategic development of board of directors

Board of directors. The information related to ground including anti-crisis caution, alternatives is given to Improvement of the information base for the process of acceptance of mana -gerial decisions by a board of direc -tors and a common stockholders' meeting Form alternative ways to counteract factors that arise in the crisis from the external environment

Removing the negative influences of risk on corporate activity

Assessment of the existence of crisis signs, their quantitative characteristics and the prediction of their influences on corporate work Presence of information for making decision regarded to relatively possible anti-crisis measures The identification of crisis process and tendencies of their development in separate subsystem of corporate functioning

Decrease of influence of crisis phenomena of internal and external environment or adaptation for these phenomena The determination of consequences of plantation of anti-crisis programs, which are the basis for further activity of stabilization

Quantitative and qualitative assessment of crisis consequences: Determents and instruments which are necessary for liquidation of crisis Information about internal and external environment of corporation-this is the base of formation of new strategy, including anti-crisis precautionary information

erning. Board of directors. based corporate

It is possible to adopt by the common stockholders' meeting 
To put the listed measures of strategic crisis management into operation and to get all of the needed results in a short period of time, with minimum resources, it is advisable to:

- Improve the quality of information, as the provision of timely and full information at all stages of decision-making promotes a successful overcoming of a crisis

- Take a quick reaction with foresight about the crisis situation. The suddenness of a crisis and the negative consequences demand from managers urgent information-analysis. Every demonstration of signs of an emerging crisis situation must be immediately examined and taken into account

- Realize strategic planning. It is the most important factor for stability and corporate development in conditions of dynamic changes in the external environment. The effectiveness of a strategy determines the appropriate external characteristics of a corporation, its position in the market, both overall and in the external environment

- Raise the quality of common decisions, organize discussions of problems and take into account all points of view to decrease the probability of the leader acting alone

- Take measures for crisis management in the directions of: Financial-economic activity, the culture of strategic management, the monitoring of the internal and external environments and the selection of rational criteria for making decisions

\section{CONCLUSION}

The success of strategic crisis management depends on timely identification of the crisis itself and the application of the most efficient methods for its removal. Successful strategic management is possible only with the use of an expenditure approach to the crisis situation and the use of a number of strategic and tactical methods of strategic management. The strategic methods are liquidation of corporations, creation of new corporate structures, regularizing, modernization, amalgamation, diversification, restructuring and reengineering. Readjustment, downsizing and bankruptcy are identified as being among the appropriate tactical methods of crisis management.

Early diagnosis of a crisis in the financial activity of a plant, a speedy response to different crisis phenomena, adequate reaction by corporations to real financial danger and full realization of the firm's inner potential in order to eliminate the crisis-all of these are necessary for effective strategic crisis management. Every stage in the development of a crisis situation is characterized by a number of functions and objectives which must be planned and implemented for effective strategic management to overcome the crisis.

At the stage of crisis, caution is necessary to provide a diagnosis of the role of external circumstances, an assessment of possible consequences of negative factors and the realization of preventative measures. It is necessary to recognize and illustrate the signs of crisis, to analyze the causes of it, to identify the type and the likely depth of the crisis and to negotiate anti-crisis programs. Assessment of post-crisis conditions, determination of controlled and uncontrolled crisis factors, the development of new strategies and the selection and realization of a strategy are all necessary to overcome the consequences of the crisis.

The key role for strategic crisis management applies to integrated actions of parties to corporate governance (stockholders' meetings, the Board of Directors, an operating agency and a review committee). Indeed, every objective of strategic crisis management at different stages contains the directions of certain actions, responsible authorities and the expected results of the mobilization of specific management functions. The listed instruments of anti-crisis measures are obligatory as a matter of caution in managing crisis situations and their onset.

Relative to directions of further research in strategic crisis management, it should be pointed out that it is important to reform strategic management processes and to pay attention to common tendencies and also to take into account the particularities of strategic management, marketing approaches and the growth of innovative activity for overcoming crisis phenomena.

\section{REFERENCES}

Bacon, T.R., 2006. What People Want: A Manager's Guide to Building Relationships That Work. 1st Edn., Illustrated, Mountain View, Davies-Black Publishing, ISBN-10: 0891062165, pp: 242.

Brace, R., 2012. Treasury and Cash Management: Corporate Cash Management in a Time of Crisis. Global Finance. September 2012.

Campbell, A. and S. Sinclair 2009. Using the crisis to create better boards. Proceedigs of the McKinsey Quarterly, Oct., 1-7, Insights and Publications. 
Cipriani, M. and A. Guarino, 2008. Herd behavior and contagion in financial markets. J. Theor. Econ., 8: 154. DOI: $10.2202 / 1935-1704.1390$

Ferguson, N., 2012. The Ascent of Money: A Financial History of the World. Penguin. 1st Edn., Illustrated, London, Penguin, ISBN-10: 0718194004, pp: 441.

Fried, J., 2012. Who Really Drove the Economy into the Ditch. 1st Edn., Illustrated, New York, Algora Publishing, ISBN-10: 0875869432, pp: 326.

Greyser, S.A., 2009. Corporate Brand Reputation and Brand Crisis Management. Manag. Decis., 47: 590602. DOI: $10.1108 / 00251740910959431$

Hellsloot, I., 2007. Review of The Politics of Crisis Management: Public Leadership under Pressure. J. Contingencies Crisis Manag., 15: 168-169.

James, E.H. and L.P. Wooten, 2007. Leadership as (Un) usual: How to Display Competence in Times of Crisis. Organizati. Dynamics, 34: 141-152. DOI: 10.1016/j.orgdyn.2005.03.005

James, E.H. and L.P. Wooten, 2010. Leading Under Pressure: From Surviving to Thriving Before, During and After a Crisis. 1st Edn., Illustrated, New Yorka, Routledge, ISBN-10: 1841697915, pp: 282.

Kindleberger, C.P. and R.Z. Aliber, 2011. Manias, Panics and Crashes: A History of Financial Crises. 6th Edn., llustrated, Hoboken, Palgrave Macmillan, ISBN-10: 0230365353, pp: 356.
Lutz, R.A., 1999. Guts: The Seven Laws of Business That Made Chrysler the World's Hottest Car Company. 1st Edn., Illustrated, New York, Wiley, ISBN-10: 0471357650, pp: 226.

Pauly, J.J. and L.L. Hutchison, 2005. Moral fables of public relations practice: The tylenol and exxon valdez cases. J. Mass Media Ethics, 20231-249. DOI:10.1207/s15327728jmme2004_2

PB, 2009. Jay lorsch with the assistance of joe bower, clayton roseand suraj srinivasan-corporate governance initiative. Harvard business school working knowledge. Perspectives from the Boardroom.

Reinhart, C. and K. Rogoff, 2011. This Time is Different: Eight Centuries of Financial Folly. 1st Edn., Illustrated, Princeton, Princeton University Press, ISBN-10: 0691152640, pp: 463.

Shiller, R.J., 2012. The Subprime Solution: How Today's Global Financial Crisis Happened and What to Do About It. 1st Edn., Illustrated, Princeton, Princeton University Press, ISBN-10: 0691156328, pp: 196.

Weiner, D., 2006. Crisis communications: Managing corporate reputation in the court of public opinion. The Workplace, March/April. 